\title{
Synaptojanin-1 plays a key role in astrogliogenesis: possible relevance for Down's syndrome
}

\author{
F Herrera ${ }^{1}$, Q Chen $^{1}$, WH Fischer ${ }^{2}$, P Maher ${ }^{1}$ and DR Schubert ${ }^{\star, 1}$
}

There is increasing interest in gliogenesis as the relevance of glia to both brain development and pathology becomes better understood. However, little is known about this process. The use of multidimensional protein identification technology (MudPIT) to identify changes in phosphoprotein levels in rat neural precursor cells treated with cytokines or retinoic acid showed that phosphorylation of the catalytic subunit of phosphatidylinositol-4,5-bisphosphate 3-kinase (PI3K p110 $\alpha$ ) and dephosphorylation of the inositol phosphatase synaptojanin-1 were common to the gliogenic stimuli. Although PI3K was found to be involved in both neuro- and astrogliogenesis, synaptojanin-1 was specifically involved in astrogliogenesis of neural precursor cells. The role of synaptojanin-1 in astrogliogenesis was further confirmed by analysis of neuron- and glia-specific markers in synaptojanin-1 knockout mouse brain. Additional experiments showed that the Sac1-like phosphatase domain of synaptojanin-1 is responsible for the observed astrogliogenic effect. Our results strongly indicate that phosphatidylinositol metabolism plays a key role in astrogliogenesis. The relevance of our findings for Down's syndrome pathology is discussed.

Cell Death and Differentiation (2009) 16, 910-920; doi:10.1038/cdd.2009.24; published online 13 March 2009

Astrocytes are the major cell population in the brain and play an essential role in its development, normal function and pathology. ${ }^{1}$ However, the mechanisms underlying the generation of astrocytes are little understood. Neurogenesis precedes gliogenesis during development, ${ }^{2}$ and embryonic neurons seem to regulate the onset of gliogenesis by secretion of factors into the extracellular space. ${ }^{3}$ Probably the best known gliogenic factors are the interleukin-6 (IL-6) family of cytokines (i.e. leukemia inhibitory factor (LIF), IL-6, IL-11, oncostatin M, cardiotrophin-like cytokine/cytokine-like factor-1 (CLC/CLF), cardiotrophin-1 (CT-1) and ciliary neurotrophic factor (CNTF)) ${ }^{3-7}$ The TGF- $\beta$ superfamily of cytokines (i.e. transforming growth factor $\beta$ (TGF- $\beta$ ), activins, bone morphogenetic proteins (BMPs) and growth and differentiation factors (GDFs)) can enhance the gliogenic effect of IL-6 family members. ${ }^{5,8}$ There is also evidence for a role of retinoic acid in gliogenesis, but its mechanism of action remains almost completely unknown, the retinoic acid receptor $\alpha$ (RAR $\alpha$ ) being the only identified mediator of this process. ${ }^{9,10}$ Besides secreted factors, cell-to-cell contact also seems to be very relevant to gliogenesis, as activation of the Notch pathway, which requires the binding of Notch receptors to their ligands in the membranes of neighboring cells, promotes gliogenesis as compared with neurogenesis during development. ${ }^{11,12}$

Phosphorylation pathways play a key role in the transduction of signals from the extracellular medium to the ultimate cellular response, and thus they determine cell behavior and fate. Gliogenesis is not an exception, for the IL-6 family of cytokines binds to and activates its membrane receptors, which have tyrosine kinase activities. These receptors trigger the JAK/STAT phosphorylation pathway leading to the expression of the astroglial marker GFAP. ${ }^{3,4,7}$ The members of the TGF- $\beta$ superfamily of cytokines also bind to and activate their membrane receptors, which in turn phosphorylate and activate Smad proteins. Smad proteins form heterodimers that strongly enhance STAT3-induced GFAP expression. ${ }^{5}$ Finally, although phosphorylation pathways are clearly involved in the effects of retinoic acid, ${ }^{13,14}$ there is no report on the role of these pathways in retinoic acidinduced glial differentiation.

The aim of this study was to identify the kinases or phosphatases involved in gliogenesis. Our results led us to synaptojanin-1, an inositol phosphatase that plays an important role in synaptic vesicle recycling and clathrinmediated endocytosis. ${ }^{15}$ We find that this phosphatase is involved in astrogliogenesis, but not in neurogenesis. A possible role for synaptojanin-1 in the brain features of Down's syndrome can be deduced from our results and earlier reported observations.

\section{Results and discussion}

Characterization of glial differentiation in the HCN-B27 clone of rat adult hippocampal precursor cells. HCN-B27 is a clone derived from the rat adult hippocampal cell line $\mathrm{HCN} .{ }^{16}$

${ }^{1}$ Cellular Neurobiology Laboratory, The Salk Institute for Biological Studies, La Jolla, CA, USA and ${ }^{2}$ Peptide Biology Laboratory, The Salk Institute for Biological Studies, La Jolla, CA, USA

${ }^{*}$ Corresponding author: DR Schubert, Cellular Neurobiology Laboratory, The Salk Institute for Biological Studies, 10010 North Torrey Pines Road, La Jolla, CA 920371099, USA. Tel: + 1858453 4100; Fax: 858535 9062; E-mail: schubert@salk.edu

Keywords: synaptojanin-1; gliogenesis; retinoic acid; cytokine; Down's syndrome

Abbreviations: MudPIT, multidimensional protein identification technology; LIF, leukemia inhibitory factor; CT-1, cardiotrophin-1; CNTF, ciliary neurotrophic factor; BMPs, bone morphogenetic proteins; RAR $\alpha$, retinoic acid receptor $\alpha$; CLC/CLF, cardiotrophin-like cytokine/cytokine-like factor-1

Received 22.7.08; revised 30.1.09; accepted 10.2.09; Edited by D Kaplan; published online 13.3.09 
Unlike the original cell line, the B27 clone is able to grow in the absence of growth factors and laminin, but it still has neural precursor cell properties, for 95-99\% of the cells express the neural precursor cell markers Musashi, Sox-2 and Nestin (Figure 1a, left, middle) and are able to form neurospheres (Figure 1a, right). In addition, they are able to differentiate into neurons and astrocytes. ${ }^{17}$ Glial differentiation can be induced by the IL- 6 and TGF- $\beta$ families of cytokines, retinoic acid, fetal bovine serum (FBS) or combinations of these factors, with different efficiencies as determined by increases in the expression of the glia-specific protein GFAP and in the number of cells positive for this protein (Figure $1 b$ and $c$ ). In spite of the clear increase in expression of GFAP upon gliogenic stimulation, $\mathrm{HCN}-\mathrm{B} 27$ cells fail to express the mature glial markers $\mathrm{S} 100 \beta$, GLAST and GLT-1 (two glutamate transporters), SPARC protein or CD44 under any of the experimental conditions tested in this study (data not shown). On the other hand, the number of cells that are positive for precursor cell markers Nestin and Sox-2, as well as the expression levels of Sox-2, decreases upon exposure of the cells to most of the gliogenic stimuli (Figure $1 \mathrm{~b}$ and $\mathrm{c}$ ).
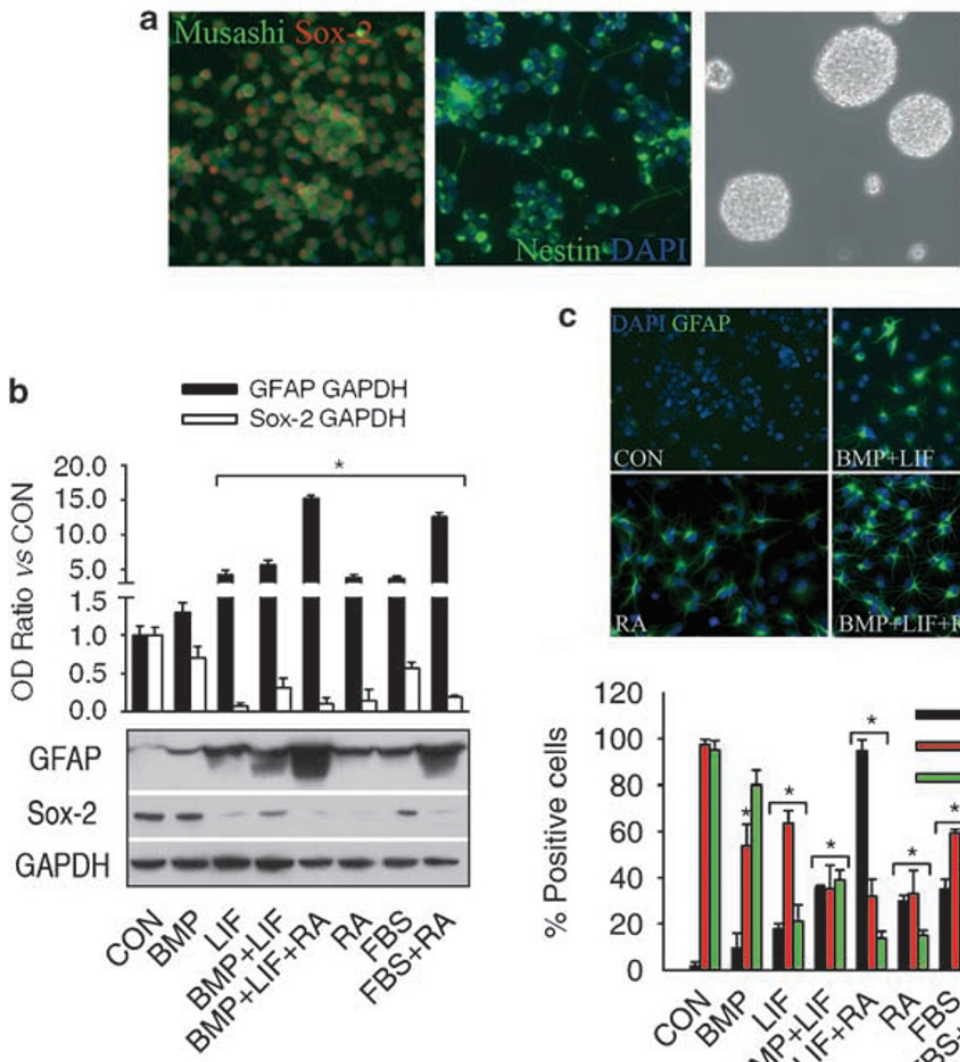

C
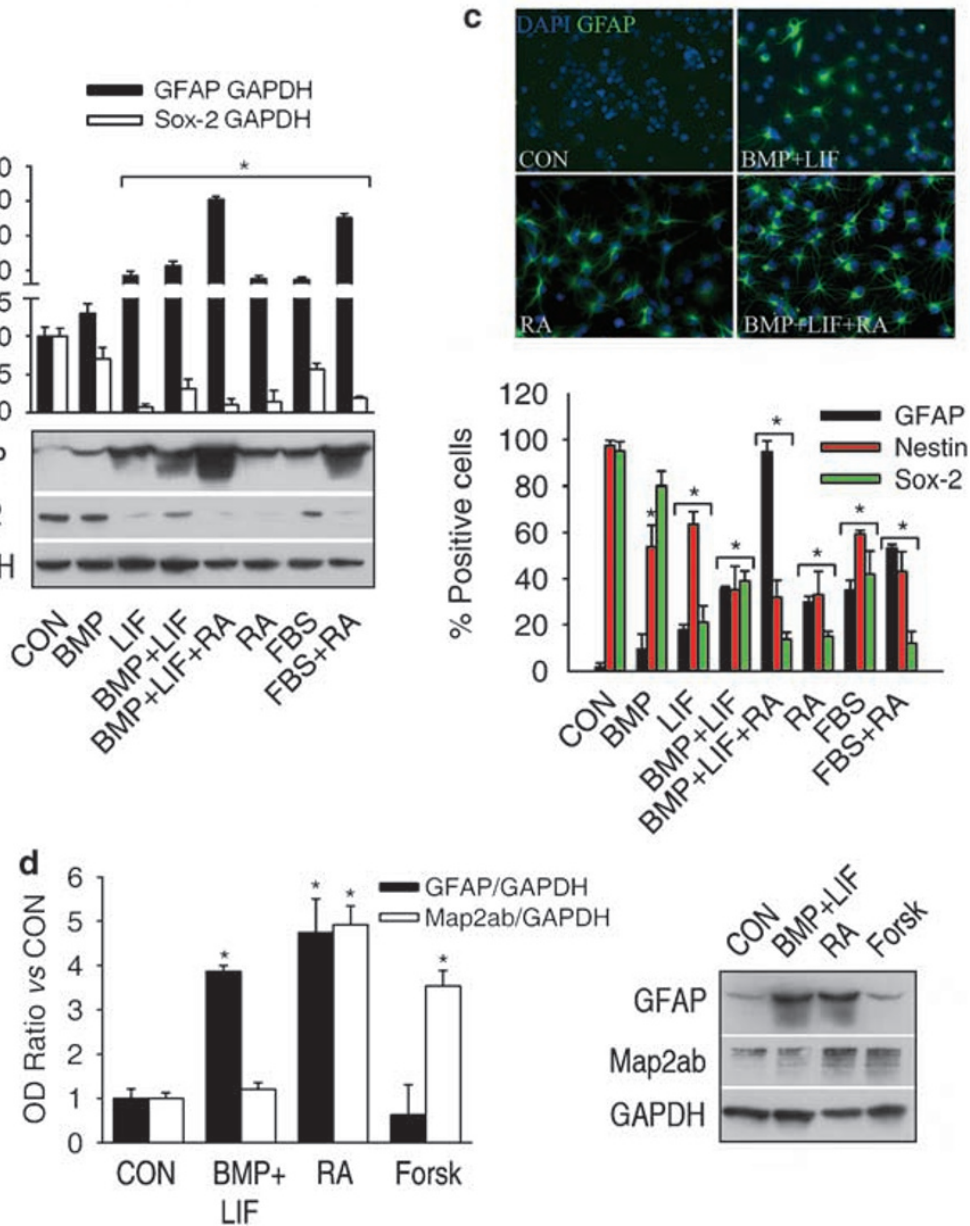

Figure 1 Glial differentiation in the HCN-B27 clone of adult rat hippocampal precursor cells. (a) The B27 clone of hippocampal precursor cells expresses the neural precursor markers Sox-2 (left, red nuclear staining), Musashi (left, green cytoplasmic staining) and Nestin (middle, green cytoplasmic staining) and are able to form neurospheres when grown on plastic dishes without poly-L-ornithine nor laminin. Nuclei were stained with DAPI (blue). (b) Different combinations of gliogenic stimuli induce different degrees of glial differentiation, as indicated by the increase in expression of the glial marker GFAP and the decrease in expression of the precursor cell marker Sox-2. (c) These results were confirmed by counting the cells that were positive for GFAP or precursor cell markers Nestin and Sox-2. Nuclei were stained with DAPI (blue). Cells were incubated for 4 days with the different drugs and factors; the same period of time was used in every experiment described below. The concentrations used here and in every experiment described below were BMP-2 (BMP), $50 \mathrm{ng} / \mathrm{ml}$; LIF, $50 \mathrm{ng} / \mathrm{ml}$; retinoic acid (RA), $1 \mu \mathrm{M} ; \mathrm{FBS}, 5 \% \mathrm{v} / \mathrm{v}$. (d) Cytokines only induce astrogliogenesis, retinoic acid induces both astrogliogenesis and neurogenesis, and forskolin (Forsk, $10 \mu \mathrm{M}$ ) only induces neurogenesis, as indicated by changes in the levels of the neuronal marker Map2ab and the astroglial marker GFAP. ${ }^{*}$ Significant versus control, $P<0.05$ 
These data strongly indicate that gliogenic factors induce $\mathrm{HCN}$ B27 precursor cells to leave their undifferentiated status and become immature astrocytes.

The most potent combinations of gliogenic factors are BMP2, LIF and retinoic acid (around $90 \%$ of the cells differentiated into astrocytes) or FBS plus retinoic acid (around 50\% differentiation). However, we used BMP-2 plus LIF or retinoic acid for the following experiments because they are the simplest conditions that induce a significant amount of differentiation, for BMP-2 alone or LIF alone are less potent, and FBS is an extraordinarily complex mixture of proteins, lipids and small molecules. Although the combination of BMP2 and LIF only induces glial differentiation, retinoic acid also induces neuronal differentiation, as shown by increases in the neuron-specific protein Map2ab (Figure 1d). In contrast, the adenylcyclase activator forskolin only induces neuronal differentiation (Figure 1d).

Retinoic acid and cytokines induce many changes in the phosphoproteome of precursor cells. Factors with apparently very different mechanisms of action are able to cause the differentiation of precursor cells into the same cell type. For example, both retinoic acid and the IL-6 family of cytokines induce glial differentiation but they act through completely different receptors. ${ }^{4,9}$ However, different initial stimuli for cell differentiation in the same cell type might share some common portions of the differentiation pathway. In order to identify possible common phosphorylation pathways involved in both retinoic acid- and cytokine-induced glial differentiation, the phosphoproteins from cells incubated with retinoic acid or BMP-2 and LIF for 4 days were isolated on metal affinity columns and then analyzed by multidimensional protein identification technology (MudPIT). MudPIT is a new, largely unbiased method for rapid and large-scale proteome analysis, based on coupling multidimensional liquid chromatography with tandem mass spectrometry analysis, which allows the identification of $>200$ proteins in a single run. ${ }^{18,19}$ Although the total proteome greatly exceeds this number, the analysis of a particular subset of proteins by means of this technique can give a large amount of information about a biological process at the protein level. ${ }^{20}$ We used this powerful tool for the first time to analyze the phosphoproteome during the differentiation of adult neural precursor cells.

There is a large increase in the number of phosphoproteins identified by MudPIT when cells are treated with retinoic acid or cytokines (Figure 2a, lower graph; Supplementary Table I). Western blots of total proteins with an anti-phosphotyrosine antibody further support this observation (Figure 2a, upper picture). In order to have a general view of the samples, the data obtained were classified by means of the uniprot

Figure 2 Retinoic acid and cytokines induce massive quantitative and qualitative changes in the phosphoproteome of precursor cells. (a) Retinoic acid and cytokines induce an increase in the number of phosphoproteins identified by MudPIT (graphic, bottom) and also in the phosphorylation of some tyrosine residues (western blot, top). (b) When the proteins identified by MudPIT were classified by means of the Uniprot database (www.uniprot.org) according to their cellular localization (top graphic) or their molecular function (bottom graphic), the results showed that there are changes inconstitution of the phosphoproteome of precursor cells after incubation with retinoic acid or cytokines. *Significant versus control, $P<0.05$ database (www.uniprot.org). The classification of the samples by their cellular localization or molecular function showed that not only the quantity of phosphoproteins but also the quality of the samples changed upon gliogenic stimulation (Figure 2b).

a
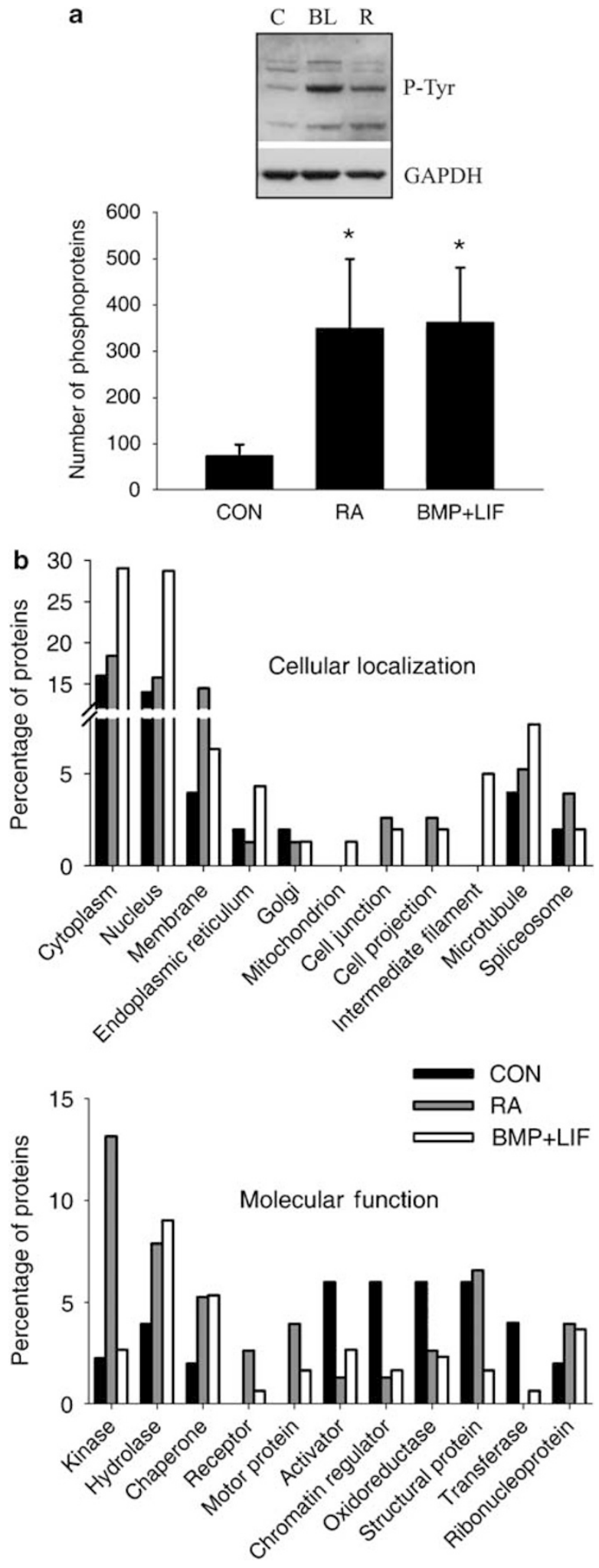
Table 1 Kinases and phosphatases (with their correspondent GI numbers) whose phosphorylation state changes after incubation with retinoic acid or cytokines

\begin{tabular}{|c|c|c|c|}
\hline GI number & Common phosphorylations (in RA and BMP+LIF but not in CON) & $\begin{array}{l}\text { Also induced } \\
\text { by Forsk }\end{array}$ & $\begin{array}{l}\text { P13K- } \\
\text { dependent }^{\mathrm{a}}\end{array}$ \\
\hline $\begin{array}{l}109464719 \\
109485997\end{array}$ & $\begin{array}{l}\text { Phosphatidylinositol-4,5-bisphosphate 3-kinase catalytic subunit } \alpha \text { isoform } \\
\text { Mitogen-activated protein kinase kinase kinase kinase } 4 \text { isoform } 1 \text { (NIK) }\end{array}$ & $\begin{array}{l}\text { No } \\
\text { Yes }\end{array}$ & $\begin{array}{l}\text { Yes } \\
\text { Yes }\end{array}$ \\
\hline $\begin{array}{l}94400809 \\
94370595 \\
94377177 \\
109475468 \\
109499493\end{array}$ & $\begin{array}{l}\text { Common dephosphorylations (in CON but not in RA or BMP+LIF) } \\
\text { Synaptojanin-1 (synaptic inositol-1,4,5-trisphosphate 5-phosphatase 1) } \\
\text { (Segment } 1 \text { of 2) Traf2 and NCK interacting kinase (TNIK) } \\
\text { Receptor-type tyrosine-protein phosphatase zeta precursor (R-PTP-zeta) } \\
\text { Inositol polyphosphate-5-phosphatase B } \\
\text { BMP2 inducible kinase }\end{array}$ & $\begin{array}{l}\text { No } \\
\text { Yes } \\
\text { Yes } \\
\text { Yes } \\
\text { Yes }\end{array}$ & $\begin{array}{l}\text { Yes } \\
\text { Yes } \\
\text { Yes } \\
\text { Yes } \\
\text { No }\end{array}$ \\
\hline $\begin{array}{l}3241856 \\
109493692 \\
109494796 \\
4558873 \\
5733095 \\
20988799 \\
109475613 \\
109478244 \\
109494196 \\
109503199 \\
109503303 \\
109469632\end{array}$ & $\begin{array}{l}\text { Phosphorylation events specific to RA (only in RA) } \\
\text { DNA-dependent protein kinase catalytic subunit } \\
\text { DNA-dependent protein kinase catalytic subunit (DNA-PK catalytic subunit) } \\
\text { DNA-dependent protein kinase catalytic subunit (DNA-PK catalytic subunit) } \\
\text { Testis-enriched protein tyrosine phosphatase } \\
\text { Tyrosine kinase TYK2 } \\
\text { Ptk2 protein (focal adhesion kinase 1)(FAK1) } \\
\text { Mitogen-activated protein kinase kinase kinase } 6 \text { (ASK2) } \\
\text { Mitogen-activated protein kinase kinase kinase kinase } 5 \text { (GCKR) } \\
\text { Ephrin type-A receptor } 6 \text { precursor (EHK-2) } \\
\text { Interleukin-12 receptor } \beta \text {-1 chain precursor (IL-12R-beta1) } \\
\text { Serine/threonine-protein kinase Nek1 (NimA-related protein kinase 1) } \\
\text { Inositol polyphosphate-5-phosphatase E }\end{array}$ & $\begin{array}{l}\text { No } \\
\text { No } \\
\text { No } \\
\text { No } \\
\text { No } \\
\text { No } \\
\text { No } \\
\text { No } \\
\text { No } \\
\text { No } \\
\text { No } \\
\text { Yes }\end{array}$ & $\begin{array}{l}\text { Yes } \\
\text { Yes } \\
\text { Yes } \\
\text { Yes } \\
\text { Yes } \\
\text { Yes } \\
\text { Yes } \\
\text { Yes } \\
\text { No } \\
\text { No } \\
\text { No } \\
\text { No }\end{array}$ \\
\hline 94408289 & $\begin{array}{l}\text { Dephosphorylation events specific to RA (present in CON and BMP+LIF but not in RA) } \\
\text { Insulin receptor substrate } 4\end{array}$ & Yes & No \\
\hline $\begin{array}{l}203474 \\
12248185 \\
20151205\end{array}$ & $\begin{array}{l}\text { Phosphorylation events specific to } B M P+L I F \text { (only in } B M P+L I F \text { ) } \\
\text { Creatine kinase } \\
\text { Nuclear ubiquitous casein kinase and cyclin-dependent kinase substrate } \\
\text { Crystal structure of a transition state mimic of the catalytic subunit of cAMP-dependent } \\
\text { protein kinase }\end{array}$ & $\begin{array}{l}\text { No } \\
\text { No } \\
\text { No }\end{array}$ & $\begin{array}{l}\text { ND } \\
\text { ND } \\
\text { ND }\end{array}$ \\
\hline $\begin{array}{l}27882143 \\
109463815 \\
114145515\end{array}$ & $\begin{array}{l}\text { Wnk4 protein } \\
\text { Pantothenete kinase } 1 \text { (Pantothenic acid kinase 1) (mPank1) (mPank) } \\
\text { Protein kinase N3 }\end{array}$ & $\begin{array}{l}\text { No } \\
\text { No } \\
\text { No }\end{array}$ & $\begin{array}{l}\text { ND } \\
\text { ND } \\
\text { ND }\end{array}$ \\
\hline 109499587 & $\begin{array}{l}\text { Dephosphorylation events specific to BMP+LIF (present in CON and RA but not in BMP+LIF) } \\
\text { Ephrin type-A receptor } 5 \text { precursor (EHK-1) }\end{array}$ & No & ND \\
\hline
\end{tabular}

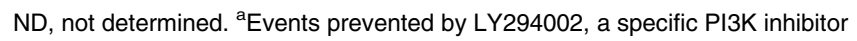

Since a large number of phosphoproteins were present in the MudPIT data from each sample (see Supplementary Table I for non-filtered results), we had to apply a series of filters in order to prioritize the analysis. First, proteins that were present in all groups were removed, for their phosphorylation is most likely constitutive and irrelevant to the differentiation process. Second, we only looked at kinases and phosphatases (Table 1). Third, those kinases or phosphatases that appear in only one of the gliogenic conditions as well as in the control group, and those that appear only in the retinoic acid- or cytokine-treated groups, were considered events most likely to be specific to each of these processes. Fourth, we compared the phosphoproteins from cells treated with gliogenic stimuli with the phosphoproteins from cells treated with forskolin, which induces only nerve differentiation. The only two events that were common to retinoic acid and cytokines and not present in cells after incubation with forskolin were the phosphorylation of PI3K and the dephosphorylation of synaptojanin-1.

PI3K is involved in glial differentiation induced by retinoic acid or cytokines. The $\alpha$ catalytic subunit of $\mathrm{PI} 3 \mathrm{~K}$ is phosphorylated only after treatment with retinoic acid or cytokines (Table 1), indicating that it is activated. The
PI3K pathway was reported to be involved in cytokine-induced glial differentiation, ${ }^{6,8}$ but this is the first time it is shown to be involved in retinoic acid-induced gliogenesis. Phosphorylation of Akt and mTOR, downstream mediators of the PI3K pathway, was observed after incubation with either retinoic acid or cytokines, confirming that the PI3K pathway is indeed activated by the gliogenic stimuli (Figure 3a). In the case of the combination of cytokines, our results indicate that BMP-2 is responsible for this activation. In order to determine whether this activation is relevant to the differentiation induced by retinoic acid or cytokines, we incubated the cells with these factors and with or without LY294002 (2-(4-morpholinyl)-8phenyl-4H-1-benzopyran-4-one, $10 \mu \mathrm{M})$. LY294002 is a highly potent and specific inhibitor of PI3K which acts on the ATPbinding site of the enzyme. Inhibition of PI3K with LY294002 prevented glial differentiation induced by cytokines, and both glial and neuronal differentiation induced by retinoic acid ,as defined by western blotting and cell counts of immunostained GFAP-positive cells (Figure $3 b$ and d).

Given the critical role that PI3K plays in the differentiationinducing effects of retinoic acid, we wanted to identify the important downstream substrates of this pathway. To this end, we extracted the phosphoproteins from cells treated with retinoic acid plus LY294002 and identified those changes in 
a

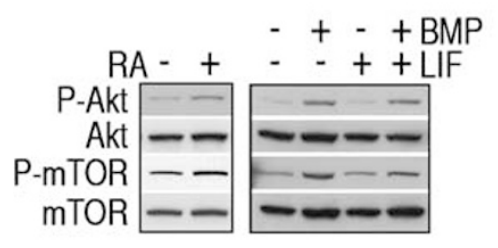

b

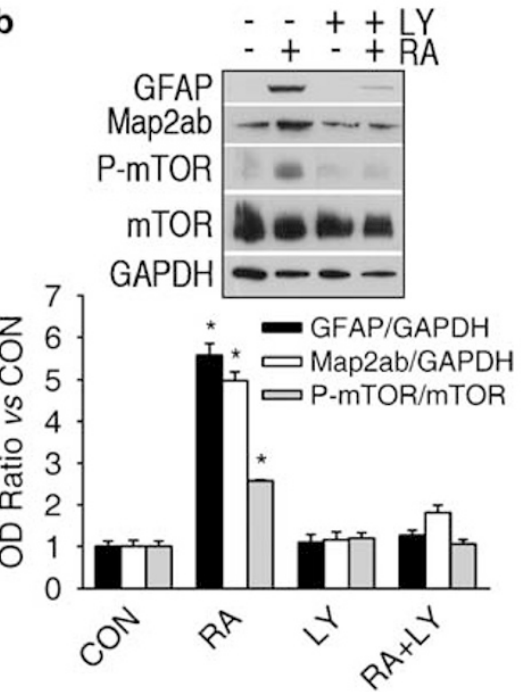

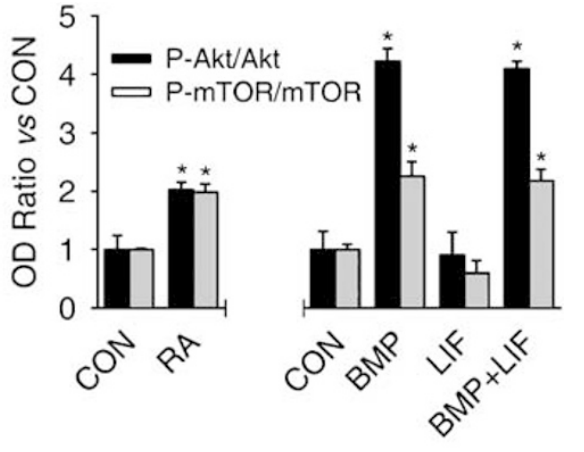

C
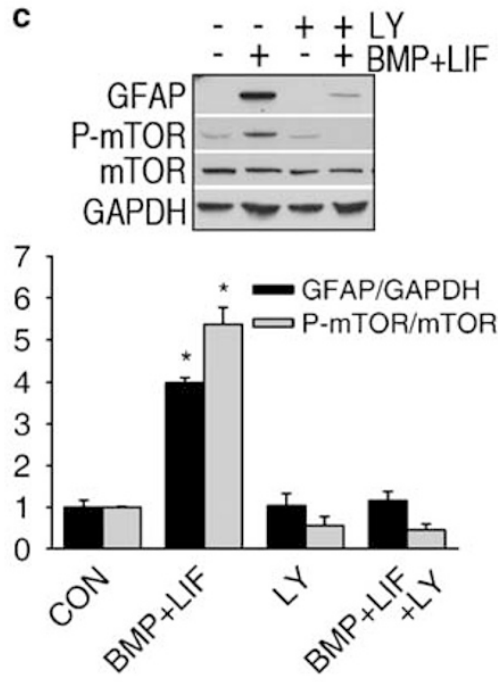

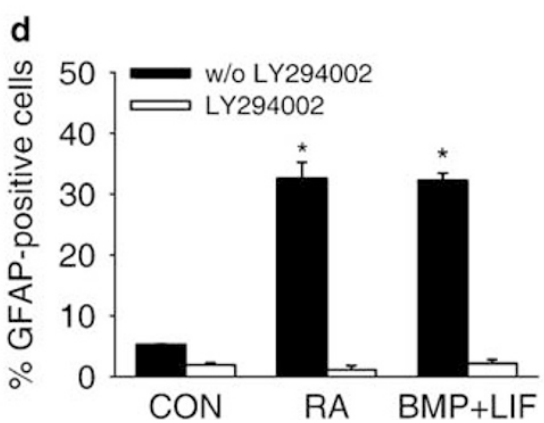

Figure 3 PI3K is involved in astrogliogenesis induced by retinoic acid or cytokines. (a) The PI3K pathway is activated after incubation with cytokines (BMP + LIF) or retinoic acid (RA), as indicated by the increases in the phosphorylation of Akt and mTOR, two kinases downstream of PI3K. (b-d) Incubation with the specific PI3K inhibitor LY294002 (LY, $10 \mu \mathrm{M})$ prevents glial differentiation by either retinoic acid (b) or cytokines (c), and neuronal differentiation by retinoic acid (d). Inhibition of PI3K by LY294002 is confirmed in all cases by preventing the increase in MTOR phosphorylation. The results obtained by western blot were confirmed by cell counting of GFAP-positive cells after the different treatments (d). ${ }^{*}$ Significant versus control, $P<0.05$

the phosphorylation state that are dependent on PI3K (i.e., prevented by LY294002) (Table 1). It is noteworthy that around $65 \%$ of the changes induced by retinoic acid are prevented by the PI3K inhibitor, either among the kinases and phosphatases or in the whole phosphoprotein sample (Supplementary Table I), confirming that PI3K plays an important role in retinoic acid-induced differentiation and signaling. The dephosphorylation of synaptojanin-1 by retinoic acid was also prevented by LY294002, indicating that this event is downstream PI3K activation.
Synaptojanin-1 is involved in astrogliogenesis in vitro. Although synaptojanin-1 is mostly expressed in the synaptic terminals of neurons, our results indicate that it can also be expressed in precursor cells or, to a lesser extent, in primary cultures of astrocytes (Supplementary Figure 1). MudPIT results indicate that synaptojanin-1 is dephosphorylated by the gliogenic stimuli (Table 1), and an earlier report shows that the 5-phosphatase activity of synaptojanin-1 is activated by dephosphorylation and inactivated by phosphorylation on tyrosine residues. $^{21}$ In order to confirm 

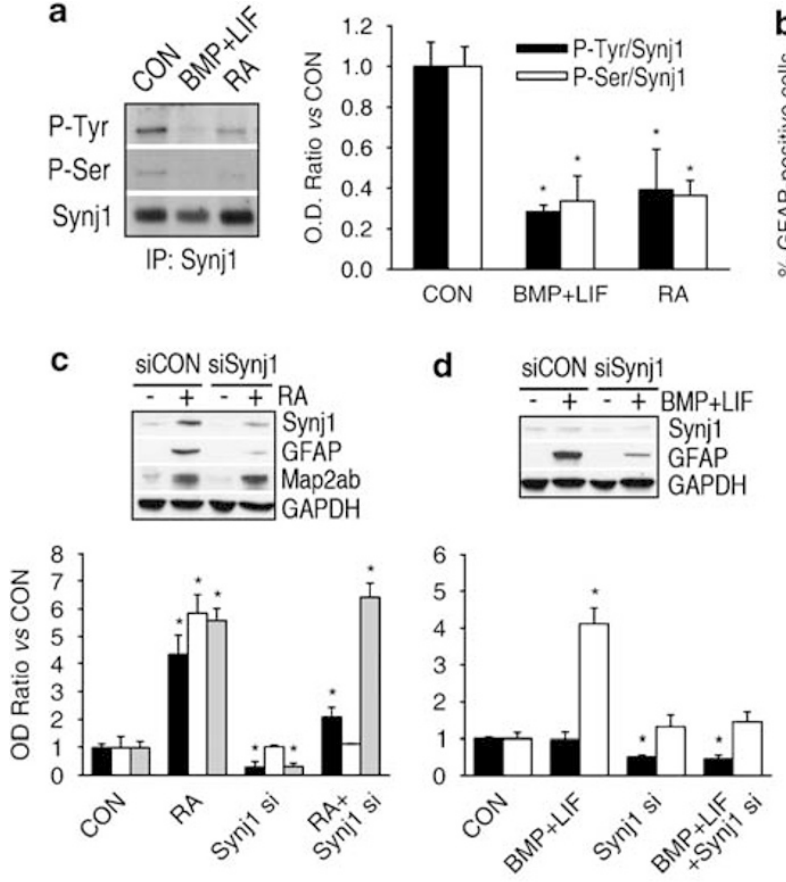

e
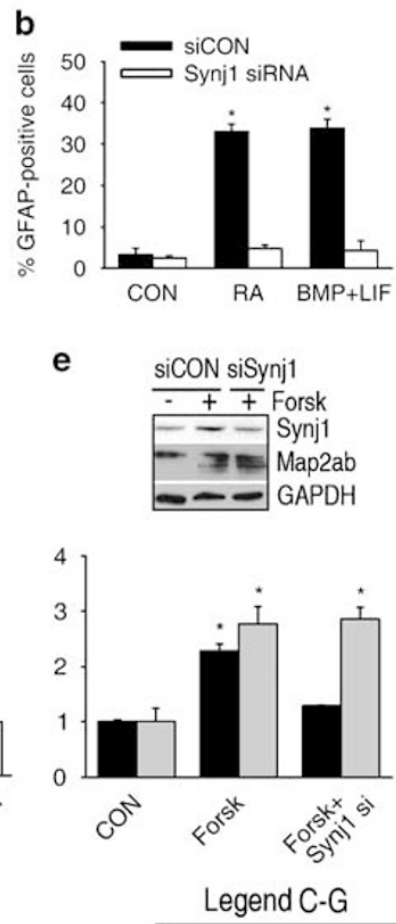

f
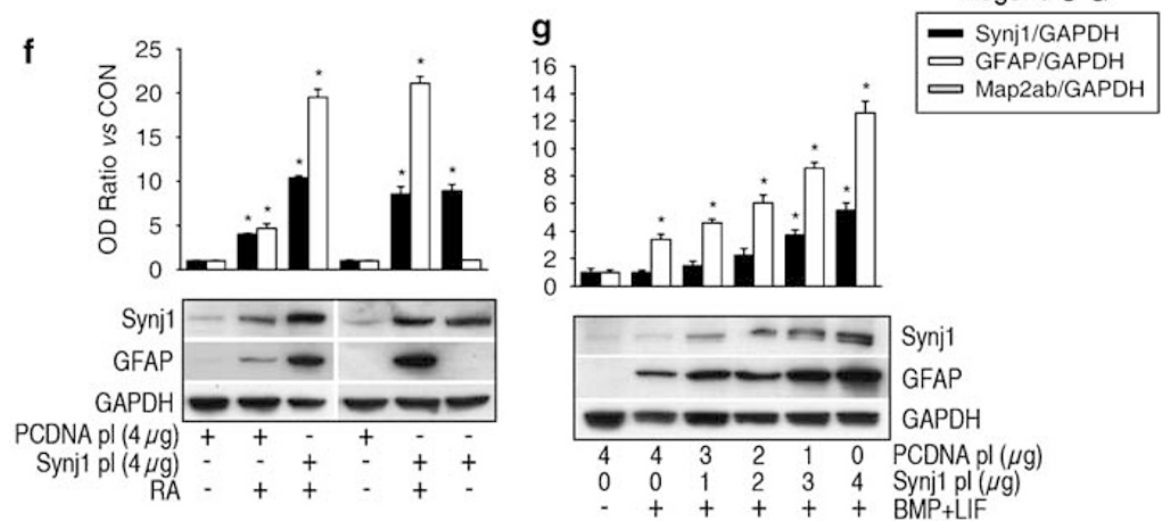

Figure 4 Synaptojanin-1 (Synj1) is involved in astrogliogenesis but not in neurogenesis in vitro. (a) Serine and tyrosine residues of synaptojanin-1 are dephosphorylated after incubation of precursor cells with the gliogenic stimuli, as shown by western blots of phosphotyrosine and phosphothreonine antibodies on synaptojanin-1 immunoprecipitates. (b-d) Downregulation of synaptojanin-1 expression by siRNA (10 nM, final concentration) prevents the increase in GFAP expression (western blot) and the number of astrocytes (immunocytochemistry) induced by either retinoic acid $(\mathbf{b}, \mathbf{c})$ or cytokines $(\mathbf{b}, \mathbf{d})$, but not the increase in Map2ab expression induced by retinoic acid (c). (e) Forskolin induces a slight increase in synaptojanin-1 expression, and the inhibition of this increase by siRNA against synaptojanin-1 does not prevent the increase in Map2ab expression. $(\mathbf{f}, \mathbf{g})$ Overexpression of synaptojanin-1 (1-4 $\mu \mathrm{g}$ of plasmid DNA per $10^{6}$ cells was used for transfection) potentiates astrogliogenesis in the presence of retinoic acid (f) or cytokines (g) but it does not induce astrogliogenesis by itself (f). *Significant versus control, $P<0.05$

MudPIT results and know which specific residues were subjected to dephosphorylation, HCN-B27 cells overexpressing synaptojanin-1 were incubated with or without retinoic acid or cytokines, the total proteins isolated and immunoprecipitated with an anti-synaptojanin-1 antibody, and blotted with antibodies against phosphotyrosine, phosphothreonine and phosphoserine (Figure 4a). No phosphorylation of synaptojanin-1 was detected on threonine residues under any of these circumstances, but a clear dephosphorylation of serine and tyrosine residues is observed after incubation with the gliogenic stimuli.

The synaptojanin-1 gene is located on chromosome 21 in humans and the brains of patients with Down's syndrome have higher levels of synaptojanin-1 expression. ${ }^{22}$ There is also an increase in the number and size of astrocytes in Down's syndrome brain ${ }^{23}$ as well as in the brains of Ts65Dn mice, a mouse model of Down's syndrome. ${ }^{24}$ These mice have a partial trisomy of chromosome 16 in a location containing the synaptojanin-1 gene. ${ }^{24}$ In contrast, synaptojanin-1 knockout mice are smaller than their littermate controls, indicating a general role for synaptojanin-1 in the development. ${ }^{15}$ The brains of synaptojanin- 1 knockout mice are also smaller. These differences in size appear postnatally, which is the stage of development when gliogenesis mainly occurs. As astrocytes are the major cell population in the brain, the decrease in brain size might be caused by a diminished 

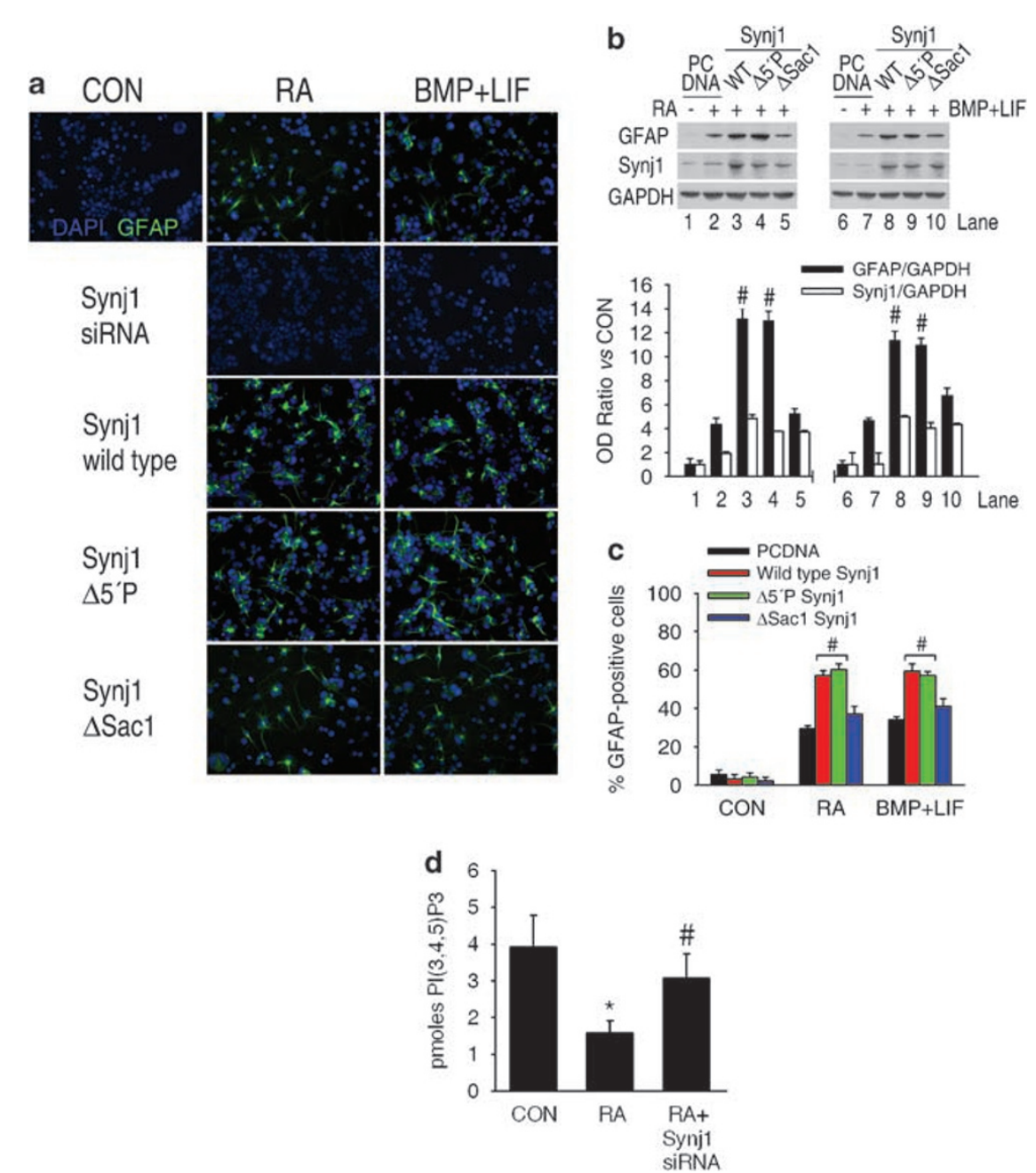

Figure 5 Potential role for phosphatidylinositol metabolism in astrogliogenesis. (a-c) Although overexpression of either wild-type synaptojanin-1 (Synj1 WT) or a mutant lacking the 5-phosphatase activity (Synj1 $\Delta 5^{\prime} \mathrm{P}$ ) potentiates glial differentiation by retinoic acid or cytokines, overexpression of a mutant lacking the Sac1-like phosphatase activity (Synj1 $\Delta$ Sac1) does not enhance it. Similar results were obtained by western blot (b) and immunocytochemistry (a, c). Nuclei were stained with DAPI (blue). "Significant versus RA or BMP + LIF plus PCDNA. (d) Retinoic acid induces a decrease in the intracellular concentration of PI $(3,4,5) \mathrm{P} 3$, which is almost completely recovered by the knockdown of synaptojanin-1. Phosphatidylinositols were extracted from $10^{7}$ cells and assayed following the manufacturer's specifications. ${ }^{*}$ Significant versus CON; \#significant versus RA

astroglial population. Therefore, we explored the possible relationship between synaptojanin-1 and astrogliogenesis.

Retinoic acid and forskolin, but not cytokines, induce an increase in synaptojanin-1 expression (Figure 4c-e). Downregulation of the expression of synaptojanin-1 by siRNA prevented glial differentiation induced by cytokines and retinoic acid, but not the neuronal differentiation induced by retinoic acid or forskolin (Figures $4 \mathrm{~b}-\mathrm{e}$ and $5 \mathrm{a}$ ), strongly indicating that synaptojanin-1 is exclusively involved in astrogliogenesis, but not in neurogenesis. Overexpression of synaptojanin-1 by itself does not induce glial differentiation, but it potentiates glial differentiation in the presence of gliogenic stimuli (Figure $4 \mathrm{f}$ and $\mathrm{g}$ ). The observations that (1) forskolin increases synaptojanin-1 expression but does not induce synaptojanin-1 dephosphorylation or gliogenesis; (2) cytokines induce synaptojanin-1 dephosphorylation and gliogenesis but do not increase synaptojanin-1 expression; and (3) over-expression of synaptojanin-1 induces an increase in glial differentiation only in the presence of gliogenic stimuli strongly indicate that the critical point for inducing gliogenesis is not the increase in expression of synaptojanin-1, but its activation.

\section{A possible role for phosphatidylinositol metabolism in} astrogliogenesis. Synaptojanin-1 has a dual phosphatase activity: a 5-phosphatase domain specifically removes a phosphate from the D-5 position of phosphoinositides and inositol polyphosphates, and a suppressor of actin 1 (Sac-1)like domain has a 3-, 4-, and 5-phosphatase activity and therefore could catalyze a wider spectrum of reactions. ${ }^{25}$ At least the 5-phosphatase activity of synaptojanin-1 seems to be regulated by the dephosphorylation of tyrosine residues, ${ }^{21}$ and we observed that there is tyrosine and serine dephosphorylation of synaptojanin-1 after incubation with gliogenic stimuli (Figure 4a). In order to know which of these phosphatase domains was responsible for the 
pro-gliogenic effect of synaptojanin-1, we overexpressed either wild-type synaptojanin-1, a mutant lacking the 5-phosphatase activity, or a mutant lacking the Sac1-like phosphatase activity $^{26}$ and analyzed their effect on retinoic acid-induced astrogliogenesis. We found that overexpression of either the mutant lacking Sac1-like phosphatase activity or the double mutant does not enhance gliogenesis as the overexpression of either the wild-type or the 5-phosphatase mutant forms of synaptojanin-1 do (Figure 5a-c). These results indicate that the Sac1-like phosphatase domain of synaptojanin-1 is responsible for the pro-gliogenic effect of synaptojanin-1.

Both PI3K and synaptojanin-1 are major regulators of inositol metabolism and signaling in the brain, ${ }^{27-29}$ and we found that they are involved in astrogliogenesis, indicating that inositol metabolism could play an important role in astrogliogenesis. The main substrate of $\mathrm{PI} 3 \mathrm{~K}$ in vivo is $\mathrm{PI}(4,5) \mathrm{P} 2$, giving rise to $\mathrm{PI}(3,4,5) \mathrm{P} 3$, and synaptojanin-1 is a major $\mathrm{PI}(3,4,5) \mathrm{P} 3$ and $\mathrm{PI}(4,5) \mathrm{P} 2$ 5-phosphatase in the brain. ${ }^{15,27}$ Accordingly, we observed that retinoic acid induces a decrease in $\mathrm{PI}(3,4,5) \mathrm{P} 3$ levels and that this decrease is prevented by the knockdown of synaptojanin-1 (Figure $5 d$ ). Nevertheless, a direct hydrolysis of $\mathrm{PI}(3,4,5) \mathrm{P} 3$ or $\mathrm{PI}(4,5) \mathrm{P} 2$ is most likely catalyzed by the 5-phosphatase domain of synaptojanin-1, because phosphoinositides with phosphates in adjacent positions are poor substrates of the Sac1-like domain. ${ }^{25}$ On the other hand, the Sac1-like domain could regulate the levels of these phosphoinositides indirectly, by means of the hydrolysis of PI4P or PI5P, for example, to $\mathrm{PI}{ }^{25}$ The availability of PI4P or PI5P can be actually limiting for the generation of $\mathrm{PI}(3,4,5) \mathrm{P} 3$ by $\mathrm{PI} 3 \mathrm{~K}$, for $\mathrm{PI}(4,5) \mathrm{P} 2$ is produced mainly by the phosphorylation of PI4P at position 5 or of PI5P at position $4 .^{30}$ Another possible mechanism could be the regulation of $\mathrm{PI} 3 \mathrm{P}$ and/or $\mathrm{PI}(3,5) \mathrm{P} 2$ levels, because $\mathrm{PI} 3 \mathrm{~K}$ can produce them by phosphorylation of $\mathrm{PI}$ or $\mathrm{PI5P}$, respectively, and synaptojanin-1 Sac1-like domain could regulate their levels by catalyzing the dephosphorylation of $\mathrm{PI}(3,5) \mathrm{P} 2$ to PI3P. However, more complex schemes for a role of phosphatidylinositol metabolism in astrogliogenesis, not necessarily centered on $\mathrm{PI}(3,4,5) \mathrm{P} 3$ or $\mathrm{PI}(3,5) \mathrm{P} 2$, cannot be ruled out.

Synaptojanin-1 is involved in astrogliogenesis in vivo. To confirm our in vitro observations, the expression of glial and neuronal markers in synaptojanin-1 knockout mouse brain was analyzed. Expression of the neuronal markers Map2ab, $\beta$ III tubulin, synaptotagmin and synaptophysin does not change in synaptojanin-1 knockout mice versus controls (Figure 6a). On the other hand, expression of the glial markers GFAP, GLT1, GLAST, SPARC and CD44 is down-regulated in knockout mice compared with wild-type mice, whereas expression of the glial marker $S 100 \beta$ remains unchanged (Figure 6a). These results could indicate that synaptojanin-1 knockout mice brains have less astrocytes than their littermate controls, or that the total number of a

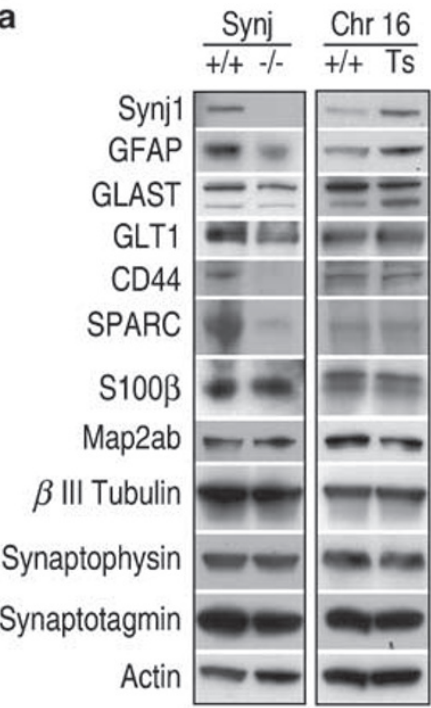

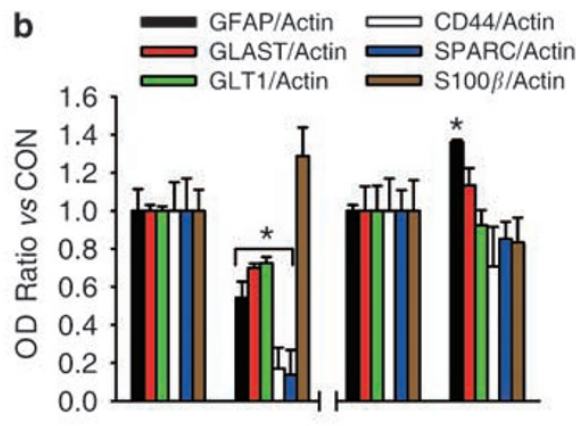

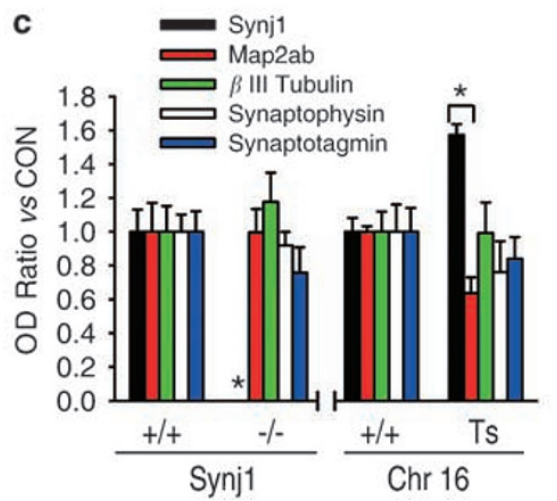

Figure 6 Synaptojanin-1 levels are directly related to astroglial content in vivo. (a) Representative western blots of total proteins extracted from brains of synaptojanin-1 knockout mice, Ts65Dn mice and their respective littermate controls. On the left, synaptojanin-1 knockout mouse brain (Synj1, $-1-$ ) shows lower levels of the astroglial markers GFAP, GLAST, GLT1, CD44 and SPARC than the brain of littermate controls (Synj1, $+1+$ ), but no changes are observed in the expression of the astroglial marker S100 $\beta$ and the neuronal markers Map2ab, $\beta$ III tubulin, synaptophysin and synaptotagmin. On the right, Ts65Dn mouse brain (Chr 16, Ts) shows higher levels of synaptojanin1 expression and the astroglial marker GFAP than the brain of littermate controls (Chr16, $+/+$ ), but Map2ab expression is decreased and no changes were observed in the expression of any other neuronal or glial markers. (b, c) Densitometric and statistical analyses of the experiments described in (a). ${ }^{*}$ Significant versus control, $P<0.05$ 
astrocytes is the same but they are not normal. We find the first possibility more likely, for five out of six glial markers were decreased and, in spite of the general agreement that it is a glial marker, $\mathrm{S} 100 \beta$ is found not only in astrocytes but also in oligodendrocytes and neurons. ${ }^{31,32}$ In fact, all of the astroglial markers are found in other cell types, ${ }^{33-36}$ but in the case of GFAP, in addition to astrocytes, it is found only in radial glia or precursor cells, which are either not present in the adult brain or found in a very small number. Furthermore, whether adult nerve precursor cells actually express GFAP is still a matter of discussion. ${ }^{16,37}$ Whether there are changes in the number or in the quality of astrocytes, it is clear that astrogliogenesis is not normal in synaptojanin-1 knockout mice, supporting our observations in vitro that synaptojanin-1 is involved in astrogliogenesis. The fact that no change is observed in the neuronal markers indicates that neurogenesis is normal in the knockout mice, further supporting our in vitro results.

Finally, given that (1) Ts65Dn mice have a partial trisomy of the chromosome 16-containing synaptojanin-1 gene and (2) it has been shown earlier that Ts65Dn mouse astrocytes are larger than normal and more abundant, it was predicted that the expression levels of both synaptojanin-1 and glial markers would be elevated in this model of Down's syndrome. Figure $6 \mathrm{~b}$ and $\mathrm{c}$ shows that Down's syndrome mouse brain has a $50 \%$ increase in synaptojanin-1 expression and $36 \%$ increase in GFAP expression. Although the expression of the other glial markers tested did not change significantly, our results still support the original observation that astrocytes are more abundant and larger in Ts65Dn mouse brain, which was exclusively based on immunohistochemistry with GFAP. ${ }^{38}$ The fact that no other glial marker is altered indicates the existence of an anomalous gliogenesis that can be easily explained by the large genetic complexity underlying Down's syndrome. Expression of the neuronal markers $\beta$ III tubulin, synaptophysin and synaptotagmin does not change, but a slight decrease in Map2ab expression is observed (Figure 6c).

The above data indicate that synaptojanin- 1 is involved in astrogliogenesis but not in neurogenesis, and offer a plausible link between the increase in synaptojanin-1 expression and the increased GFAP reactivity in Down's syndrome brain. ${ }^{22,23}$ Together with published results, the data support a key role for synaptojanin-1 and inositolphosphate homeostasis in brain development and the histopathological features of Down's syndrome brain. ${ }^{28}$ Most brain pathologies are classically associated with neuronal dysfunction or neuronal loss. However, astrocytes are essential for neuronal function, survival and differentiation, ${ }^{1,39}$ and growing evidence indicates that they might be involved in neuronal dysfunction or damage. ${ }^{1}$ In this sense, individuals with Alexander's disease, a disorder caused by mutations in the GFAP gene, have defects in both glial and neuronal function, severe loss of white matter and very often mental retardation, the hallmark of Down's syndrome. ${ }^{40}$ Very recently, synaptojanin-1 has been shown to contribute to the cognitive deficits observed in mouse models of Down's syndrome. ${ }^{28}$ Little is known about the molecular determinants of Down's syndrome pathology, but our data support a possible role for astrocytes or astrogliogenesis in this disease.

\section{Materials and Methods}

Materials. Cell culture plastics were acquired from Falcon (Becton Dickinson, Franklin Lakes, NJ, USA) and culture media, supplements and additives were obtained from Invitrogen (Carlsbad, CA, USA), unless otherwise indicated. Retinoic acid and forskolin were purchased from Sigma (St. Louis, MO, USA). Human recombinant BMP-2 was obtained from R\&D systems (Minneapolis, MN, USA) and LIF from Chemicon (Temecula, CA, USA). LY294002 was obtained from LC Laboratories (Woburn, MA, USA). 'Milo' antibody against Rat synaptojanin-1 was a generous gift from Dr. Peter McPherson (McGill University, Montreal, Canada) and antibodies against glutamate transporters GLT1 and GLAST were a generous gift from Dr. Jeffrey D Rothstein (Johns Hopkins University, Baltimore, MD, USA). Wildtype rat synaptojanin-1 expression plasmid and synaptojanin-1 knockout and control littermate mouse brains were a kind gift from Dr. Pietro Di Camilli (Yale University School of Medicine, New Haven, CT, USA). Expression plasmids for synaptojanin-1 mutants lacking 5-phosphatase and Sac1-like phosphatase activity were a kind gift from Dr. Timothy A Ryan (Weill Medical College, Cornell University, New York, NY, USA). The siRNA against rat synaptojanin-1 and siRNA control were obtained from Dharmacon (Chicago, IL, USA). Lipofectamine 2000 (Invitrogen) was used for synaptojanin-1 siRNA and plasmid lipofection following the manufacturer's instructions. ELISA kit for $\mathrm{PI}(3,4,5) \mathrm{P} 3$ determination was purchased from Echelon Biosciences Incorporated (Salt Lake City, UT, USA) and used according to the manufacturer's instructions.

Cell cultures and animals. The $\mathrm{HCN}$ rat adult hippocampal precursor cell line was kindly provided by Drs. J Ray and FH Gage (The Salk Institute for Biological Studies, La Jolla, CA, USA). The B27 clone was isolated from these cells in our laboratory as described earlier. ${ }^{17}$ HCN-B27 cells were maintained in Neurobasal medium plus $1 \mathrm{mM}$ glutamine, $1 \times$ penicillin/streptomycin mixture and $1 \times \mathrm{B} 27$ supplement (minus antioxidants) (Invitrogen). For experiments, cells were seeded into polyornithine-coated dishes in DMEM/Ham F12 1:1 medium (Omega Scientific, Tarzana, CA, USA) plus $1 \mathrm{mM}$ glutamine, $1 \times$ penicillin/streptomycin and $1 \times \mathrm{N} 2$ supplement (Invitrogen).

All procedures for animal studies adhered to the Guide for the Care and Use of Laboratory Animals and were approved by the Salk Institute Animal Care and Use Committee. Male Ts65Dn mice and their littermate controls were obtained from The Jackson Laboratory (Bar Harbor, ME, USA), and were housed in a temperature- and humidity-controlled environment on a 12-12 h light-dark cycle with free access to food and water. One month-old mice were anesthetized with $500 \mu \mathrm{l}$ of chloral hydrate $7 \%$ and perfused with KPBS plus protease inhibitors (Roche Diagnostics, Mannheim, Germany) for 5 min. Brains were extracted, immediately frozen on dry ice and stored at $-80^{\circ} \mathrm{C}$ for posterior analysis.

Western blot, immunoprecipitation and immunocytochemistry. Cells or brains were lysed with RIPA buffer (HEPES $50 \mathrm{mM} \mathrm{pH}$ 7.0, NaCl $150 \mathrm{mM}, \mathrm{NP}-401 \% \mathrm{v} / \mathrm{v}$, sodium dodecyl sulfate $0.1 \% \mathrm{w} / \mathrm{v}$, deoxycholic acid $0.5 \% \mathrm{w} / \mathrm{v}$, PMSF $0.1 \mathrm{mM}$, dithiothreitol $1 \mathrm{mM}$, cocktail of protease inhibitors, EDTA-free (Roche Diagnostics) and cocktail of phosphatase inhibitors II $0.01 \% \mathrm{v} / \mathrm{v}$ (Sigma)), sonicated and centrifuged at $10000 \times g$ for $10 \mathrm{~min}$ at $4^{\circ} \mathrm{C}$. Supernatants were collected and the protein concentration was quantified by the Dc protein assay (Bio-rad, Hercules, CA, USA). Fifty micrograms of protein were loaded and run on $12 \%$ acrylamide pre-cast gels (Bio-rad) and transferred to PVDF membranes for blotting. Antibodies against the following proteins were used: GFAP 1:2000 from Chemicon actin and Map2ab (1:1000) from Sigma); mTOR, phospho-mTOR (Ser2448), Akt and phospho-Akt (Ser473) (1:1000) from Cell Signaling technologies (Danvers, MA, USA); GAPDH (1:10000) from Labfrontier (Republic of South Korea); Neuronal class III $\beta$-tubulin ( $\beta$ III tubulin, antigen Tuj1, 1:2000) from Covance (Berkeley, CA, USA); GLAST (1:100); GLT1 (1:10000); S100 $\beta$ $(1: 1000)$ from DAKO (Carpinteria, CA, USA; secreted protein acidic and rich in cysteine (SPARC, 1:50) from Developmental Studies Hybridoma Bank (University of lowa, lowa, USA); synaptophysin and synaptotagmin $(1: 1000)$ from Roche Diagnostics and Milo synaptojanin-1 antibody (1:200). Immunoblots were shown by enhanced chemoluminescence (Pierce, Rockford, IL, USA) and their optic density was quantified with the Scion image free software (www.scioncorp.com).

For immunoprecipitation, the protocol supplied by Cell Signaling was followed using the Milo antibody against rat synaptojanin-1. After immunoprecipitation, western blots of the samples were carried out as described above and blotted with the antibodies against rat synaptojanin-1, phosphoserine, phosphothreonine (Qiagen, Valencia, CA, USA) and phosphotyrosine (Cell Signaling Technologies). 
For immunocytochemistry, cells were sequentially fixed with $4 \% \mathrm{w} / \mathrm{v}$ paraformaldehyde for $20 \mathrm{~min}$, washed once with phosphate buffered saline (PBS), permeabilized with $0.5 \%$ Triton- $X$ in PBS for 10 min and washed three times with PBS before blocking in $3 \%$ bovine serum albumin in PBS for $1 \mathrm{~h}$. Cells were then incubated with primary antibodies against GFAP (1:1000), Musashi $(1: 200)$, Sox-2 $(1: 200)$ or Nestin $(1: 200)$ (all from Chemicon) in blocking solution overnight at $4{ }^{\circ} \mathrm{C}$. After removal of the primary antibody, cells were sequentially washed three times with $0.5 \%$ Triton-X in PBS (10 min each); incubated with the appropriate goat anti-rabbit or anti-mouse secondary antibodies conjugated with Fluor 488 or Texas Red (1:1000, Invitrogen, ) in blocking solution for $1 \mathrm{~h}$ at room temperature; washed again three times with $0.5 \%$ Triton-X in PBS (10 min each); incubated for 20 min with a $1 \mu \mathrm{g} / \mathrm{ml}$ DAPI solution in PBS; and washed twice with PBS (10 min each). Pictures were taken with a Hamamatsu digital camera (Bridgewater, $\mathrm{NJ}$, USA) coupled to a Leica fluorescence microscope (Allendale, NJ, USA).

Phosphoprotein isolation and multidimensional protein identification (MudPIT). Phosphoproteins from cells were isolated by means of the Phosphoprotein Isolation Kit (Qiagen) according to the manufacturer's instructions. Briefly, after cell lysis, lysates were passed through metal affinity columns and the eluates containing the phosphoproteins were collected. The phosphoprotein eluates were then passed through Sephadex G-25 buffer exchange columns (GE Healthcare, Buckinghamshire, UK) following the manufacturer's directions, in order to remove salts and small molecules that would interfere with MudPIT analysis. Ten micrograms of phosphoproteins per sample were reduced with DTT $(20 \mathrm{mM})$ in $6 \mathrm{M}$ urea, followed by alkylation with iodoacetamide. After 8-fold dilution with $50 \mathrm{mM}$ ammonium bicarbonate, trypsin $(1 \mu \mathrm{g})$ was added and digestion was allowed to proceed overnight. The samples were desalted using Bond-Elut cartridges ( $50 \mathrm{mg}$, Varian, Palo Alto, CA, USA). The peptide eluate was concentrated to dryness in a vacuum centrifuge and reconstituted in $0.1 \%$ aqueous formic acid. Tandem (strong cation exchange/ reversed phase) capillary columns were packed in house. First, a capillary with integrated spray tip (75 $\mu \mathrm{m}$ ID, $10 \mu \mathrm{m}$ tip, New Objective, Woburn, MA, USA) was packed with C-18 reversed phase material (Zorbax SB-C18, $5 \mu \mathrm{m}$ particle size, Agilent, Santa Clara, CA, USA) to a length of $8 \mathrm{~cm}$. This was followed by highpressure packing with strong cation-exchange material (polysulfoethyl A, $5 \mu \mathrm{m}$ particle size, Poly LC, Columbia, MD, USA) to a length of $4 \mathrm{~cm}$. Protein digests were then bomb-loaded onto the column (Nanobaume Capillary Column Packer, Western Fluids, Wildomar, CA, USA). The column was subsequently connected to a nanoflow high-performance liquid chromatography (HPLC) (Eksigent, Livermore, CA, USA). To perform the multi-dimensional chromatography, ten $\mathrm{pH}$ steps were employed, each followed by an acetonitrile gradient. The $\mathrm{pH}$ step buffers $(\mathrm{pH} 2.5$, 3.0, 3.5, 4.0, 4.5, 5.0, 5.5, 6.0 and 8, Column Technology, Fremont, CA, USA) were loaded onto the column using an autosampler and a 3- $\mu$ l loop. The reversed phase elution was achieved by a linear gradient of $0-60 \%$ acetonitrile in $0.1 \%$ formic acid, which was used to elute the peptides within $60 \mathrm{~min}$ at a flow rate of $300 \mathrm{nl} / \mathrm{min}$. The eluate was introduced into a Thermo LTQ-Orbitrap mass spectrometer (ThermoFisher, Waltham, MA, USA) through a nano-spray source. Mass spectrometric analysis was conducted by recording precursor ion scans at a resolution of 60000 in the Orbitrap Fourier-transform analyzer followed by MS/MS scans of the top five ions in the linear ion trap (cycle time approx. $1 \mathrm{~s}$ ). An active exclusion window of $90 \mathrm{~s}$ was employed. Data were analyzed using the Mascot algorithm (Matrix Science, London, UK). This approach gave us lists of 200-300 phosphoproteins per sample, which was compared between the samples using the Scaffold program (Proteome Software, Portland, OR, USA) on a Sorcerer Solo platform (SageN, San Jose, CA, USA). Filters to reduce the number of possible target proteins were applied as described in the Results and Discussion section.

Statistical analysis. Graphs show the mean \pm standard error of three independent experiments. Data were analyzed using one-way analysis of variance followed by the Tukey post hoc test. Significance was accepted when $P<0.05$.

Acknowledgements. This work was supported by a grant to $\mathrm{FH}$ from the Instituto de Salud Carlos III/Centro Superior de Investigaciones Científicas (SALK06/02) and grants to PM, DS and WF from the NIH (AG025337) and to La Jolla Interdisciplinary Neuroscience Center (NIH NS057096). We sincerely thank Drs. Pietro de Camilli, Peter McPherson, Timothy A Ryan, Jeffrey D Rothstein, Jasodhara Ray and Fred $\mathrm{H}$ Gage for the useful material they kindly provided. We also thank Jessica Read and William Low for technical assistance and Dr. Karsten Schmidt for help with MS data analysis.
1. Croisier $E$, Graeber MB. Glial degeneration and reactive gliosis in alpha-synucleinopathies: the emerging concept of primary gliodegeneration. Acta Neuropathol (Berl) 2006; 112: $517-530$

2. Qian X, Shen Q, Goderie SK, He W, Capela A, Davis AA et al. Timing of CNS cell generation: a programmed sequence of neuron and glial cell production from isolated murine cortical stem cells. Neuron 2000; 28: 69-80.

3. Barnabe-Heider F, Wasylnka JA, Fernandes KJ, Porsche C, Sendtner M, Kaplan DR et al. Evidence that embryonic neurons regulate the onset of cortical gliogenesis via cardiotrophin-1. Neuron 2005; 48: 253-265.

4. Bonni A, Sun Y, Nadal-Vicens M, Bhatt A, Frank DA, Rozovsky I et al. Regulation of gliogenesis in the central nervous system by the JAK-STAT signaling pathway. Science 1997; 278: 477-483.

5. Nakashima K, Yanagisawa M, Arakawa $\mathrm{H}$, Kimura $\mathrm{N}$, Hisatsune $\mathrm{T}$, Kawabata $\mathrm{M}$ et al. Synergistic signaling in fetal brain by STAT3-Smad1 complex bridged by p300. Science 1999; 284: 479-482.

6. Hermanson $\mathrm{O}$, Jepsen $\mathrm{K}$, Rosenfeld MG. $\mathrm{N}$-CoR controls differentiation of neural stem cells into astrocytes. Nature 2002; 419: 934-939.

7. Rajan P, McKay RD. Multiple routes to astrocytic differentiation in the CNS. J Neurosci 1998; 18: 3620-3629

8. Rajan P, Panchision DM, Newell LF, McKay RD. BMPs signal alternately through a SMAD or FRAP-STAT pathway to regulate fate choice in CNS stem cells. J Cell Biol 2003; 161: 911-921.

9. Goncalves MB, Boyle J, Webber DJ, Hall S, Minger SL, Corcoran JP. Timing of the retinoid-signalling pathway determines the expression of neuronal markers in neural progenitor cells. Dev Biol 2005; 278: 60-70.

10. Wohl CA, Weiss $\mathrm{S}$. Retinoic acid enhances neuronal proliferation and astroglial differentiation in cultures of CNS stem cell-derived precursors. J Neurobiol 1998; 37: 281-290.

11. Chambers CB, Peng Y, Nguyen H, Gaiano N, Fishell G, Nye JS. Spatiotemporal selectivity of response to Notch1 signals in mammalian forebrain precursors. Development 2001; 128: $689-702$

12. Taylor MK, Yeager K, Morrison SJ. Physiological Notch signaling promotes gliogenesis in the developing peripheral and central nervous systems. Development 2007; 134: 2435-2447.

13. Bastien J, Plassat JL, Payrastre B, Rochette-Egly C. The phosphoinositide 3-kinase/Akt pathway is essential for the retinoic acid-induced differentiation of F9 cells. Oncogene 2006; 25: 2040-2047.

14. Lopez-Carballo G, Moreno L, Masia S, Perez P, Barettino D. Activation of the phosphatidylinositol 3-kinase/Akt signaling pathway by retinoic acid is required for neural differentiation of SH-SY5Y human neuroblastoma cells. J Biol Chem 2002; 277: 25297-25304.

15. Cremona O, Di PG, Wenk MR, Luthi A, Kim WT, Takei K et al. Essential role of phosphoinositide metabolism in synaptic vesicle recycling. Cell 1999; 99: 179-188.

16. Ray J, Gage FH. Differential properties of adult rat and mouse brain-derived neural stem/ progenitor cells. Mol Cell Neurosci 2006; 31: 560-573.

17. Schubert D, Klar A, Park M, Dargusch R, Fischer WH. F-spondin promotes nerve precursor differentiation. J Neurochem 2006; 96: 444-453.

18. MacCoss MJ, McDonald WH, Saraf A, Sadygov R, Clark JM, Tasto JJ et al. Shotgun identification of protein modifications from protein complexes and lens tissue. Proc Natl Acad Sci USA 2002; 99: 7900-7905

19. Licklider LJ, Thoreen CC, Peng J, Gygi SP. Automation of nanoscale microcapillary liquid chromatography-tandem mass spectrometry with a vented column. Anal Chem 2002; 74: 3076-3083.

20. Florens L, Washburn MP, Raine JD, Anthony RM, Grainger M, Haynes JD et al. A proteomic view of the Plasmodium falciparum life cycle. Nature 2002; 419: 520-526.

21. Irie F, Okuno M, Pasquale EB, Yamaguchi Y. EphrinB-EphB signalling regulates clathrinmediated endocytosis through tyrosine phosphorylation of synaptojanin 1. Nat Cell Biol 2005; 7: 501-509.

22. Arai $Y$, ljuin $T$, Takenawa $T$, Becker LE, Takashima S. Excessive expression of synaptojanin in brains with Down syndrome. Brain Dev 2002; 24: 67-72.

23. Mito T, Becker LE. Developmental changes of S-100 protein and glial fibrillary acidic protein in the brain in Down syndrome. Exp Neurol 1993; 120: 170-176.

24. Antonarakis SE, Lyle R, Dermitzakis ET, Reymond A, Deutsch S. Chromosome 21 and down syndrome: from genomics to pathophysiology. Nat Rev Genet 2004; 5: $725-738$

25. Guo S, Stolz LE, Lemrow SM, York JD. SAC1-like domains of yeast SAC1, INP52, and INP53 and of human synaptojanin encode polyphosphoinositide phosphatases. J Biol Chem 1999; 274: 12990-12995.

26. Mani M, Lee SY, Lucast L, Cremona O, Di PG, De CP et al. The dual phosphatase activity of synaptojanin 1 is required for both efficient synaptic vesicle endocytosis and reavailability at nerve terminals. Neuron 2007; 56: 1004-1018.

27. Woscholski R, Finan PM, Radley E, Totty NF, Sterling AE, Hsuan JJ et al. Synaptojanin is the major constitutively active phosphatidylinositol-3,4,5-trisphosphate 5-phosphatase in rodent brain. J Biol Chem 1997; 272: 9625-9628.

28. Voronov SV, Frere SG, Giovedi S, Pollina EA, Borel C, Zhang $\mathrm{H}$ et al. Synaptojanin 1-linked phosphoinositide dyshomeostasis and cognitive deficits in mouse models of Down's syndrome. Proc Natl Acad Sci USA 2008; 105: 9415-9420. 
29. Li L, Liu F, Ross AH. PTEN regulation of neural development and CNS stem cells. J Cell Biochem 2003; 88: 24-28.

30. Carricaburu V, Lamia KA, Lo E, Favereaux L, Payrastre B, Cantley LC et al. The phosphatidylinositol (PI)-5-phosphate 4-kinase type II enzyme controls insulin signaling by regulating PI-3,4,5-trisphosphate degradation. Proc Natl Acad Sci USA 2003; 100 : 9867-9872.

31. Vives V, Alonso G, Solal AC, Joubert D, Legraverend C. Visualization of S100B-positive neurons and glia in the central nervous system of EGFP transgenic mice. J Comp Neurol 2003; 457: 404-419.

32. Steiner J, Bernstein HG, Bielau H, Berndt A, Brisch R, Mawrin C et al. Evidence for a wide extra-astrocytic distribution of S100B in human brain. BMC Neurosci 2007; 8: 2

33. Mendis DB, Brown IR. Expression of the gene encoding the extracellular matrix glycoprotein SPARC in the developing and adult mouse brain. Brain Res Mol Brain Res 1994; 24: 11-19.

34. Plachez C, Martin A, Guiramand J, Recasens M. Astrocytes repress the neuronal expression of GLAST and GLT glutamate transporters in cultured hippocampal neurons from embryonic rats. Neurochem Int 2004; 45: 1113-1123.
35. Plachez C, Danbolt NC, Recasens M. Transient expression of the glial glutamate transporters GLAST and GLT in hippocampal neurons in primary culture. $J$ Neurosci Res 2000; 59: 587-593.

36. Rampon C, Weiss N, Deboux C, Chaverot N, Miller F, Buchet D et al. Molecular mechanism of systemic delivery of neural precursor cells to the brain: assembly of brain endothelial apical cups and control of transmigration by CD44. Stem Cells 2008; 26 : 1673-1682.

37. Seri B, Garcia-Verdugo JM, McEwen BS, varez-Buylla A. Astrocytes give rise to new neurons in the adult mammalian hippocampus. J Neurosci 2001; 21: 7153-7160.

38. Holtzman DM, Santucci D, Kilbridge J, Chua-Couzens J, Fontana DJ, Daniels SE et al. Developmental abnormalities and age-related neurodegeneration in a mouse model of Down syndrome. Proc Natl Acad Sci USA 1996; 93: 13333-13338.

39. Kornyei Z, Gocza E, Ruhl R, Orsolits B, Voros E, Szabo B et al. Astroglia-derived retinoic acid is a key factor in glia-induced neurogenesis. FASEB $J$ 2007; 21 2496-2509.

40. Quinlan RA, Brenner M, Goldman JE, Messing A. GFAP and its role in Alexander disease. Exp Cell Res 2007; 313: 2077-2087.

Supplementary Information accompanies the paper on Cell Death and Differentiation website (http://www.nature.com/cdd) 